\title{
The Conceptualization of the Sharing Economy as a Business Model
}

\author{
Donata Siuskaite, Vaida Pilinkiene, Dainius Zvirdauskas
}

\author{
${ }^{1}$ Kaunas University of Technology \\ K. Donelaicio st. 73, LT-44029, Kaunas, Lithuania \\ E-mail.donata.siuskaite@gmail.com,vaida.pilinkiene@ktu.lt,dainiuszv@gmail.com
}

cross $^{\text {ref }}$ http://dx.doi.org/10.5755/j01.ee.30.3.21253

\begin{abstract}
The paper analyses the recently emerged and rapidly growing phenomenon of sharing economy. The assessment of an extensive amount of publications issued by Lithuanian and foreign researchers has revealed the problem that in most cases a simplified business model is still being applied to all sharing economy initiatives despite of their evident differences. The use of abstraction method, systematic approach and comparative research enabled the authors to examine the formation and disclosure of different sharing economy definitions and provide a revised one as well as to establish the chronological process of the development of the phenomenon. Moreover, the research also presents the peculiarities of the sharing economy as a new business model by highlighting its characteristics and dimensions and emphasizing the social, economic and ecological key factors and the main drivers such as monetization of excess or unused assets, increasing financial flexibility, the impact of venture capital, access over ownership, increasing urbanization etc. The outcome of this research is the conceptual sharing economy business model that allows not only to understand the functioning of the sharing economy better but also to grasp the differences of already existing initiatives and to find opportunities to create new ones. This may help for researchers, practitioners, and policymakers not only guide future research and policy intervention but also find valuable insights for sharing economy business models development and better foreseen the results of this phenomena.
\end{abstract}

Keywords: Sharing Economy; Collaborative Economy; Business Model; Digital Platforms; Users, Peer-to-peer.

\section{Introduction}

In the early 1990's, society's materialistic values, developed by the rise of advertising and marketing, initiated a new era of consumption. Reckless hyper consumption has caused a number of economic, ecological and social crises, with the consequences of which (such as financial constraints, resource decay, global climate change, growing poverty and inequality) the whole world is fighting nowadays. Globalization and the development of digital technologies were the main motives for the new generations of the human race to seek for smarter, more responsible ways of consumption. Fuelled by the internet and social networks, the sharing economy - phenomenon based on the users' collaboration and seeking to maximize the usage of the already existing assets and resources - emerged.

The sharing economy, stemming from the intensified society's desire not to become passive victims of hyper consumption, freed up the underutilized resources and provided its participants with a chance to use the necessary items without acquiring them, as well as earning extra money and spending it more sensibly. By providing opportunities for the new entrants and challenging the existing market players, the sharing economy is also changing the business sector and is undeniably important to the European economic growth. The digital platforms in the five main sectors of the sharing economy facilitated around $€ 28$ billion of transactions and generated $€ 3.6$ billion revenues for its participants in 2015 alone. The experts predict the further rapid growth of the sector and its contribution to the global economy in the near future (Vaughan \& Daverio, 2016).
The subject of sharing economy has gained a lot of attention of scientists and media in the recent years. However, only a few authors analyse the phenomenon as a new market and business model. A simple but well-founded classification of sharing economy business models was proposed by Schor (2014) and later updated in the report of Codagnone \& Martens (2016). One of the most thorough empirical studies regarding the wide diversity of sharing economy business models was provided by Munoz \& Cohen (2017). Unfortunately, no Lithuanian scientific publications explore the sharing-based businesses and the wide variety models of those businesses yet.

The research problem. Despite the fact that businesses based on sharing economy principles have grown from simple peer-to-peer initiatives to gigantic and complex platforms, many foreign and Lithuanian researchers appraise only respective elements of the sharing economy in their scientific publications, hence there is still lack of a more thoroughly outlined theoretical research of the phenomenon's main points. Moreover, authors yet seem to apply one simplified business model to all sharing economy enterprises, regardless of their evident diversity. The aim of this research is to conceptualize the sharing economy as a business model and emphasize the factors and drivers influencing it. The methods used in the research are abstraction, systematic approach and comparative research.

\section{The Concept of the Sharing Economy and its} Evolution in the Context of Globalization

Sharing, or giving access to your personal property to someone seeking to meet a particular need, is closely 
connected with the evolutionary processes. According to the experts of biology and sociology, cooperation and sharing were an integral part of life even in the primitive communities. Despite of being naturally programmed to share, the members of the contemporary society by all means have tried to forget this fact. The recently emerged model of collaborative consumption is an obvious proof that sharing is being rediscovered as a desirable and encouraged behaviour. The progress of science has made it possible to share in ways and to extent that could not be imagined before, and the new technologies have removed a considerable amount of physical and psychological obstacles that once deterred our ancestors from sharing. In other words, it's not the phenomenon of sharing that is new, but the methods and ways of sharing.

The sharing economy is based on the principle that all the recourses necessary for the humanity to survive have been already discovered or produced; however, many of these resources are being spoiled, wasted or used inefficiently. Unlike in the past, when people merely shared in small limited communities, nowadays we are selling, buying, renting, borrowing things not only to (and from) our friends but strangers too. Connected by mobile technologies and social networks, people have learned to work constructively and find the balance between their interests and the common good (Buczynski, 2013).

Some of currently successfully operating sharing economy forms are just as old as the humanity itself. The historical roots of the phenomenon lie in the primitive barter but it is reckoned that the starting-point of the sharing economy is year 1978, when the article about the acts of collaborative consumption was published by Felson $\&$ Spaeth (Figure 1). Although the definition proposed by the authors was far removed from the modern concept, yet the idea of sharing things attracted the attention of academic society.

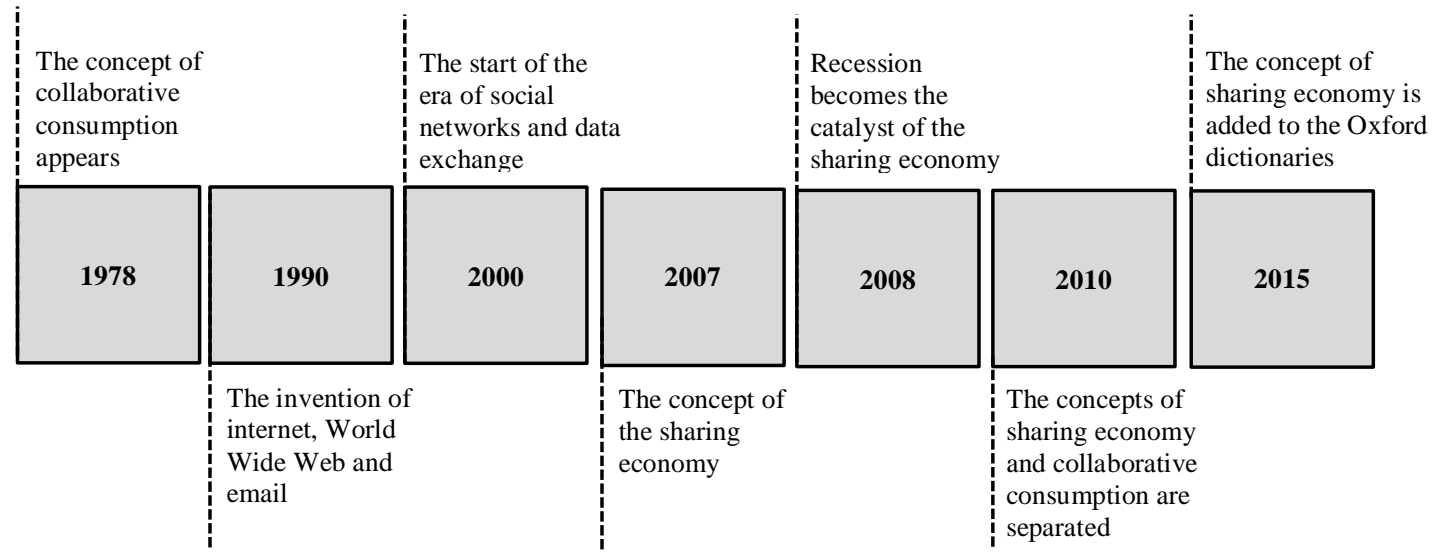

Figure 1. The Evolution of the Sharing Economy

According to Marshall (2015), the modern sharing economy began in 1990, when the first digital innovations became available to the public. The internet initiated the establishment of commercial websites (Amazon, eBay, Craigslist etc.) which performed the function of goods recirculation (Schor, 2014). The beginning of the $21^{\text {st }}$ century is considered to be the period of rapid economic and social growth of this business model. As Dudek \& Salek (2016) point out, one of the main reasons for this trend was the development of modern technology. Namely in the span of 2000-2007 the era of social networks and data sharing platforms began, and the pioneer sharing economy platforms providing car rental (Zipcar, Greenwheels), bike rental (Call a bike, City Rader), peer-to-peer lending (Zopa, Lending Club), accommodation (Couchsurfing) and other services were established.

The development of sharing economy was also influenced by the ideas of social responsibility which became popular due to the global ecological problems. Increased public awareness and a more responsible attitude to consumption obliged to search for new business models, and after the introduction of consumer trust and transaction security systems, people's interest in sharing economy began increasing exponentially. By the way, the concept of sharing economy itself was invented only in 2007 by
Lawrence Lessig, professor at Harvard Law School (Oh \& Moon, 2016).

Sharing economy reached the growth boom in 2008 after the global economic recession. Declined customers confidence, rising unemployment rates and receding purchasing power of the consumers have forced people to cut their spending and look for new ways of earning money (Goudin, 2016). The economic downturn inspired the birth of such widely known platforms like Airbnb and Uber; it also spurred the interest of media and scientists as more publications in sharing economy topic were published (Selloni, 2017).

Soon discussions regarding the correct concept of the phenomenon began. Botsman \& Rogers (2010) were the first to highlight the differences between the concepts of sharing economy and collaborative consumption. To this day, a wide variety of sharing economy synonyms - such as mesh economy, access economy, zero - marginal cost economy, gig economy, platform economy etc. - can be found in academic literature (Gobble, 2017; Selloni, 2017). Nevertheless, regardless all the debates and critique, the concept of sharing economy was added to the Oxford Dictionaries, where it was defined as "an economic system in which assets or services are shared between private individuals, either free or for a fee, typically by means of the 
Internet". Authors suggest a revised definition: the sharing economy is a modern technology-based method of whether collaboration or business management that enables the peers to allocate the already existing tangible and intangible resources free of charge or for a fee.

\section{The Characteristics and Dimensions of the Sharing Economy as a Business Model}

Since the abrupt bound of collaboration-based market, the scholars of entrepreneurship and business management science have been exploring the reasons of the remarkable phenomenon's success and finally came to a decision that the rapid development of sharing economy could not be based solely on changes in the demand and supply patterns of such services. According to researchers, the key factor behind the emergence and development of the sharing economy is a new, successful business model disrupting the principles of traditional economy (Weber, 2014).

Commonly a business model is referred to as an abstract tool that not only highlights the needs and financial opportunities of consumers, but also explains how the enterprise creates value, delivers it to the consumers and entices them to pay for it while contributing to the process of public welfare establishment (Teece, 2010, cit. from Munoz \& Cohen, 2017).

The modern global economy driven by technological progress and demographic change is moving towards a new era. Forced by the reshaping needs and values of humanity, companies must search for more sophisticated ways of creating and delivering value to consumers by introducing new business models. Recently emerged internet platforms have opened the paths for businesses to solve their client's problems in ways previously unknown and allowed people to interact in collaborative user networks. Today sharing economy based businesses are established in transport, accommodation, professional services, finance and other all major sectors of economy; nonetheless, here's still a lack of knowledge about the operation of these innovative business models (Cohen \& Kietzmann, 2014).

The business model of sharing economy initiatives is a subject discussed just as widely as the concept of the phenomenon itself. Regardless the growing complexity of the collaborative enterprises, most researchers tend to put all sharing economy businesses into a single standard frame. However, Munoz \& Cohen (2017) offer a different viewpoint. The authors collected and analysed data from 36 companies, representing different categories of sharing activities. As a result of this research, seven aspects typical to all sharing based businesses were presented:

(1) Platforms for collaboration, which bring together buyers and sellers, are considered to be the key dimension of the sharing economy business model. Platform creates digital connections between users who share their tangible and intangible resources while seeking for sustainable consumption.

(2) Under-utilized resources are the subject of nearly all sharing economy initiatives. The recourses may vary from physical objects (such as real estate, vehicles, household appliances etc.) to intangible assets (knowledge, skills, professional services etc.) of idle capacity.
(3) Peer-to-peer interaction is the third key element in sharing economy business model. Users usually interact via internet or mobile apps.

(4) Collaborative governance reflects the inclusion of consumers into the process of value creation and helps the platforms of sharing economy to balance the needs of their user and redistribute the resources.

(5) Mission-driven. The majority of sharing economy businesses not only seek for profit, but implement various social and environmental goals as well, e. g. promote environmental awareness, reduce consumerism etc.

(6) Alternative funding is also a significant part of sharing economy based initiatives. It is closely connected to the customers who are involved in the transactions as plenty of successful collaborative businesses are financed by alternative methods of funding like crowdsourcing.

(7) Leverage on technology. The role of technology in sharing economy business models is undeniable: not to mention it was the progress of information and communication technologies that initiated the birth of peer-to-peer networking, today modern digital innovations enable us with more efficient, faster and cheaper transactions.

Although there is no such a model of sharing economy that contains all seven components mentioned above, the first three dimensions - platforms, resources and P2P interaction - are considered to be fundamental. Figure 2 outlines an abstract business model of sharing economy initiatives (Cheng, 2015; Grybaite \& Stankeviciene, 2016; Petropoulos, 2017).

Authors of scientific literature (Cheng, 2015; Grybaite \& Stankeviciene, 2016; Petropoulos, 2017) usually indicate three parties that appear in the sharing economy business model:

- Services providers (also referred to as sellers), who offer their property, resources, time or skills to those in need. It can be any individual person as well as professional service providers or enterprises.

- Users (or customers), who want purchase certain goods or services in order to satisfy their needs.

- Digital platforms or mobile apps, which act as intermediaries between the first two parties.

Multisided online platforms are considered to be the disruptive innovation that led to an advanced open market. Digital platforms not only enable users and providers to communicate directly without the intervention of a third party, moreover, due to a large number of vendors provide a greater range of choice, faster, cheaper and geographically unrestricted transactions. Consumers acquiring tangible or intangible assets pay the price of it to the platform as well as the additional platform service fee which is usually calculated as a percentage of the transaction value (Petropoulos, 2017). Platform administrator later remits the payment to the seller and finally at the end of the transaction both parties leave feedback about the entire bargain and each other. 


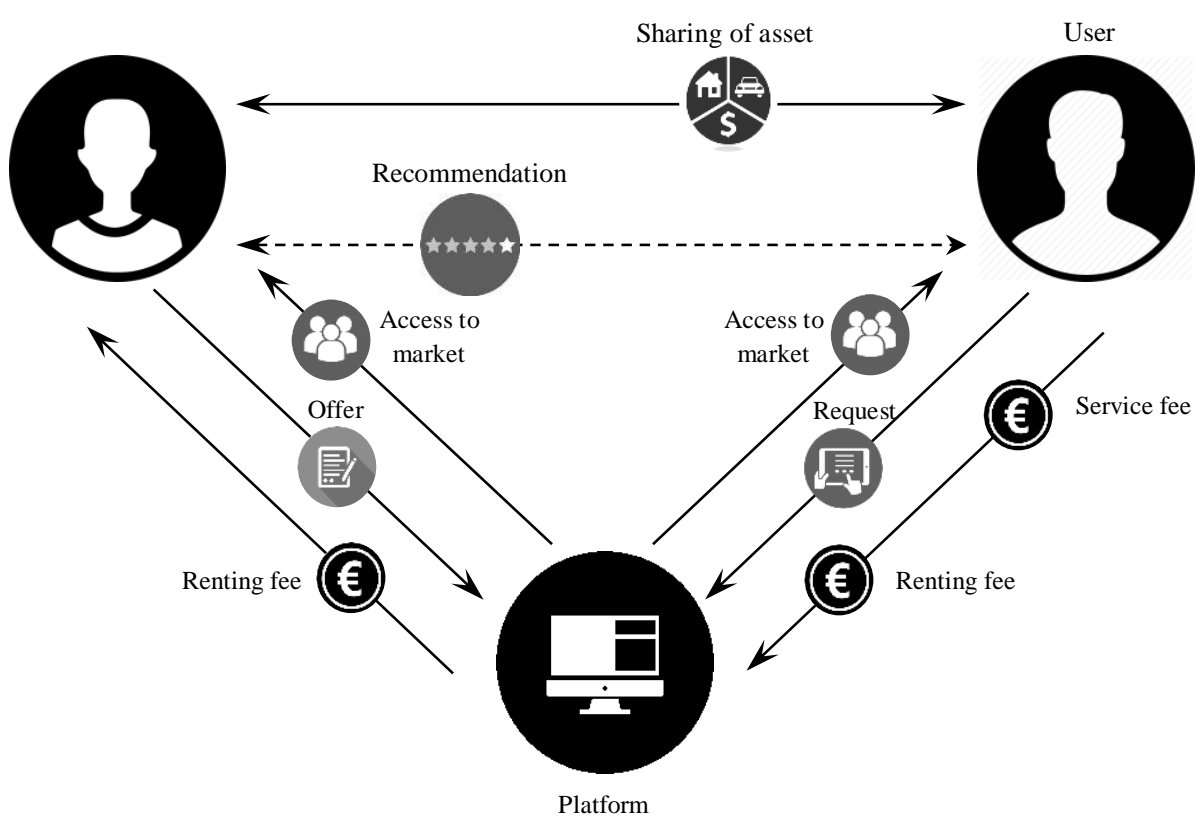

Figure 2. Sharing Economy Business Model

However, some scholars (Schor, 2014; Sundararajan, 2016; Munoz \& Cohen, 2017) are not in a haste to put all sharing economy based enterprises into the frame of this simplified business model. Codagnone \& Martens (2016) share the same opinion and emphasize the challenge of classifying online platforms due to their wide range of innovative economic and social activities. Nevertheless, the experts of sharing economy introduce different classifications of business models of this phenomenon. For example, Cohen (2016) together with Munoz created Sharing Business Model Compass (Figure 3). It is based on six key dimensions of sharing economy based business models, each of them having three different alternatives that a sharing start-up can make.

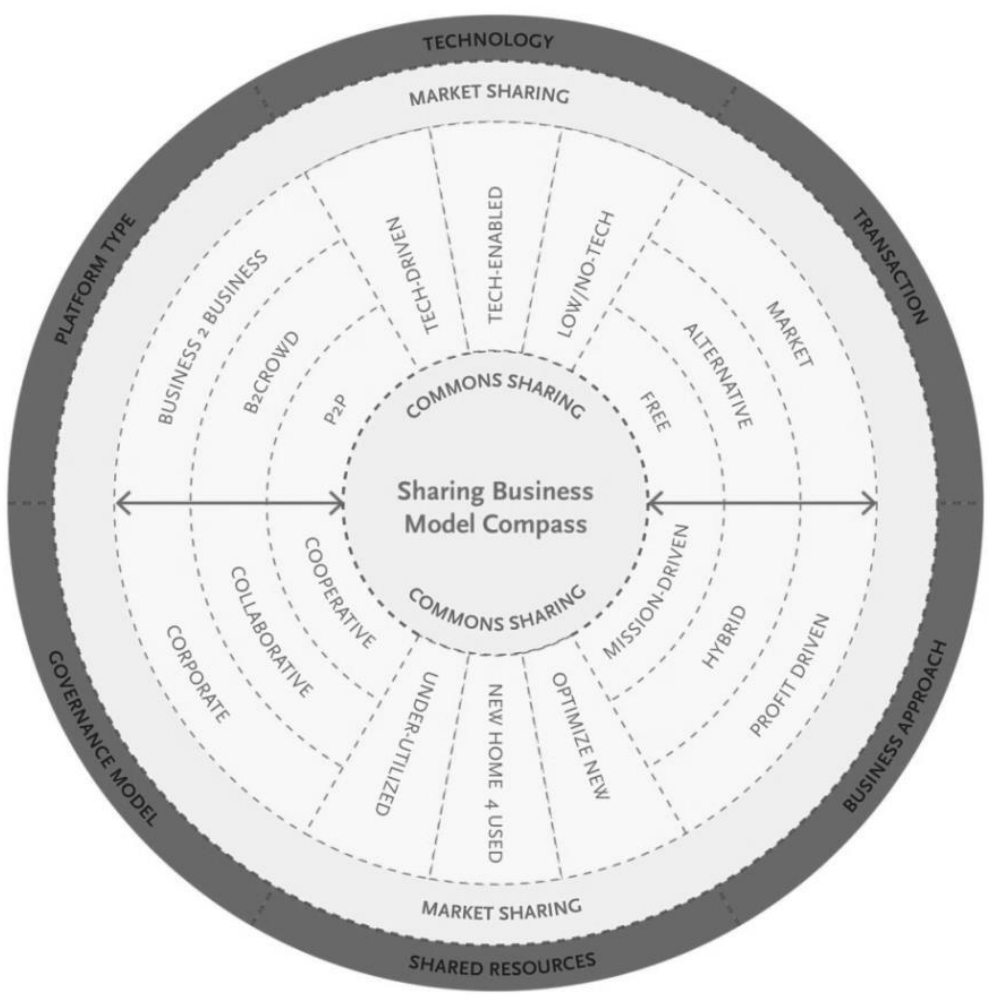

Figure 3. Sharing Business Model Compass (Source: Munoz, 2016)

In the view of technology, sharing economy businesses can be tech-driven, tech-enabled or low/no-tech. The first group of enterprises fully rely on digital platforms: transactions are carried solely online, and bargaining parts do not meet in person at all. This alternative is widely applied in crowdsourcing or P2P lending platforms. Tech- 
enabled sharing economy businesses allow their users to negotiate the details of the transaction online, but it cannot be accomplished without the meeting of users - e. g., an Uber driver must drive the passenger to their desired destination. Low/no-tech sharing initiatives do not rely on technologies and only use it as a supporting tool for their activities. The element of transaction describes a payment method used by a specific sharing economy enterprise. The most popular ones are market transactions, where pricing is based on demand. Scaled sharing economy leaders like Uber or Airbnb opt for this kind of transaction. On the other hand, alternative transactions are only starting to emerge. In this case, cash settlements are substituted by a payment method devised by the platform, like "time dollars", exchanging used goods and so on. Finally, some sharing economy initiatives offer completely free services. The dimension of business approach reflects the goals of the sharing economy based businesses. They can be profit-driven and seeking to maximize their revenue; mission-driven which means aiming for some kind of ecological, environmental or social change; or hybrid - both profit and mission driven. Regarding the resources circulating in collaborative activities, sharing initiatives may choose to either to employ already existing under - utilized assets, help finding a new owner for used items or optimise new resources by purchasing and renting unused valuables. The governance model of the platform varies from corporate to collaborative to cooperative. Corporate structures are considered to be traditional and are embraced by most venture capital funded platforms. Collaborative approaches are less popular because they require more engagement with users and other interested parties by including them in the projects funded through a particular platform. Cooperative governance model is the most liberal but due to its high degree of uncertainty only individual rules of this model are applied in sharing activities. Finally, platform type defines the types of sellers and buyers engaging in the transaction. The possible combinations are peer-to-peer (P2P), business to crowd and business to business (B2B). A total of 729 unique sharing economy business models originate from the choice of a single option within each of the six above mentioned dimensions, therefore claiming that the activities of all sharing economy businesses are based on the same principles is merely wrong. Moreover, over time platforms may change their business model due to the changes of customer preferences, priorities of their investor or expected profitability.

A rather simpler classification of sharing based businesses offered by Schor (2014), Codagnone \& Martens (2016) and Petropoulos (2017) who all believe that the operation of collaborative platforms is shaped by their market orientation and market structure (Figure 4).

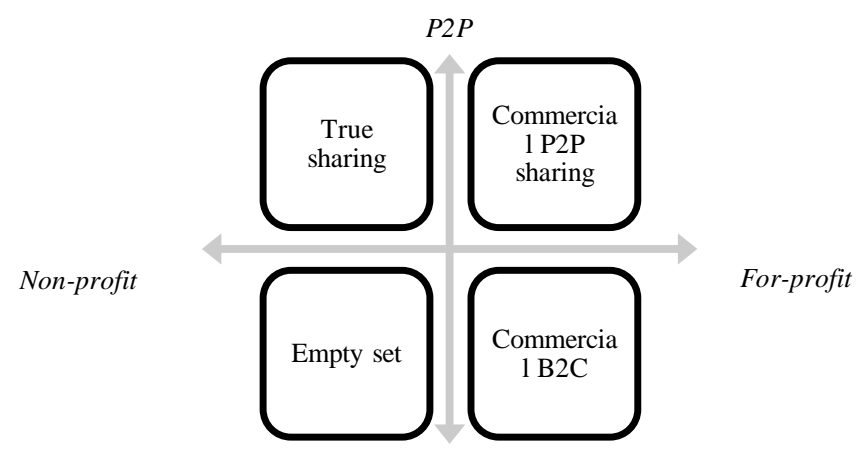

$B 2 C$

Figure 4. Two-Dimensional Matrix of Sharing Economy Initiatives

The dimension of market orientation considers whether the sharing - based business is seeking for profit or not, whereas the element of market structure assesses the type of transaction participants who can be either individual persons (peers) or businesses. According to different combinations of these alternatives, sharing economy initiatives fall into one of four quadrants. Platforms based on sharing motives specifically (e.g., tool banks, time banks, etc.) belong in the group of true sharing. They yearn to satisfy certain societal needs but do not seek for growth or profit maximization. Despite of the small number of true sharing platforms, they are essential in achieving social policy goals such as community regeneration, social inclusion and the promotion of social innovation. Commercial P2P sharing platforms (e.g., Airbnb, Uber, etc.) connect individual persons who are willing to employ their assets and earn extra money. The third quadrant is named empty set because the conception of non-profit business is an oxymoron by nature. However, in some cases companies finance certain social and philanthropic activities. Finally, the group of commercial B2C sharing encompass the cases where private enterprises (e.g., Zipcar, Citybee, etc.) provide various services to individuals for a certain fee via digital platforms. There is a disagreement in the academic world whether initiatives of this kind should be considered a part of sharing economy, since they practically are no different from normal online stores (Codagnone \& Martens, 2016).

\section{The Factors and Drivers of the Sharing Economy as a Business Model}

Sustainable consumption and production are top priority goals of EU Sustainable Development Strategy. The constant search of constructive measures that would help fighting the negative environmental and social consequences of hyper consumption and mass production has led to a consensus that sharing economy is one of them. By being based on the principles of sustainability, ethics and equal allocation or resources among the members of society, the innovative 
business model changed formerly rooted belief that only increasing consumption can maintain and raise the standards of living. The analysis of sharing economy in the light of sustainable development reveals numerous social, economic and ecological factors contributing to the success and growth of the phenomenon.

The social potential of sharing economy lies in the establishment of stronger communities and closer interpersonal relationships. Collaborative initiatives encourage people to escape the boundaries of their lives and become active members of the society (Bachnik, 2016). The following social factors are considered to be essential in promoting sharing based activities:

- Increasing number and density of world inhabitants. The exponential growth of population began in the clash of 18th and 19th centuries, when mortality was reduced and the quality of life improved due to the rapid growth of industry, scientific and technical progress and achievements in medicine. According to the United Nations, there are around 7.6 billion people living on Earth, and every year this number increases by approximately 83 million. The rising concentration of humanity enables a freer, smoother process of sharing economy and provides greater opportunities for matching demand and supply. Moreover, the development of sharing economy is also stimulated by urbanization processes because the demand for specific services (such as short-term car rental or accommodation, professional services, etc.) arises due to the moving of people from rural areas to cities and suburbs (Goudin, 2016). The sharing economy platforms offer a wide range of goods and services that satisfy the needs of consumers and provide financial benefits to the vendors.

- Promotion of sustainable development. The global ecological problems intimidate not only individual persons but business enterprises as well. Many organizations incorporate the principles of social responsibility into their organizational processes and promote the achievement of social and environmental goals. Sharing economy is also based on resource saving, consumption and ecological footprint reduction ideas.

- Need of communication. Human beings are naturally characterized by their desire to communicate and interact with the members of the ambient environment. Along with the sharing economy, new communication tools (such as social networks, blogs, mobile apps, etc.) have also emerged. The modern mass media connects incredibly large user groups with the access to nearly any information and the possibility of disseminating it to others. The new economic business model is directly dependent on how easily unfamiliar and physically distant participants can contact each other (Bockmann, 2013).

- Emergence of Millennials. According to statistic data, the most active sharing economy participants are $22-$ 35 year old. The human generation born between 1980s and the beginning of the $21^{\text {st }}$ century is considered to be more educated, far more technologically advanced and distinguished for their ethical and ecological consumer habits. The Millennials do not consider the ownership to be an essential value; on the contrary, most of them prefer access over ownership. Therefore, the sharing economy is an integral part of their lives.

- Feelings of altruism and empathy motivate individuals to empathize, sympathize and help each other in difficult situations. These feelings encourage people to donate to charities, share their assets with those in need. Bockmann (2013) suggests that these social standards are the drivers of sharing economy because they not only help people to feel useful and necessary, but also unite them in seeking for global sustainable development.

The economic dimension of the phenomenon reflects through the maximization of asset productivity. Because of the sharing economy, an asset which would be used only several times by its owner, is exploited to its maximum since it is accessible to many peers. The benefit is reciprocal: consumers save time, money and other resources, whereas vendors and services providers earn extra income (Bachnik, 2016). The main driving economic forces of the phenomenon are:

- Monetization of excess or unused assets. Many people have equipment, tools and other things that they do not use in their daily activities. Rent, lending or any other recruitment of such property as well as sharing of our specific professional skills or knowledge in many cases result in financial gain (Kathan, Matzler \& Veider, 2016).

- Increasing financial flexibility. The expansion of globalization and the accelerated rates of international communication empower with the opportunity to become financially independent by converting assets into money, in addition to becoming more flexible without purchasing unnecessary assets (Bockmann, 2013).

- Access over ownership. The sharing economy has made luxury goods accessible not only to wealthy people but to other groups of individuals as well. In addition, new opportunities for business were opened (Boumphrey, 2016).

- The impact of venture capital. One of alternative methods of funding significantly contributes to the successful development of sharing economy. A large number of sharing - based startups attract large scale investments and later used it for the further growth of their platform (Bockmann, 2013).

The ecological potential of sharing economy resides in a more efficient mechanism of resource utilization which aims to save the limited stocks that are necessary to produce goods and services. Actually, the majority of consumers, who claim to be a part of sharing economy because of the phenomenon's environmental advantage, are more educated and earn higher income. These circumstances are based on Maslow's hierarchy of needs, as environmental concerns are attributed to a higher level of Maslow's pyramid and won't be noticed until the basic human needs are met (Bocker \& Meelen, 2016). The following ecological factors are considered to be vital in the expansion of sharing economy:

- Limited natural resources and the deteriorating ecological status of our planet are reasonably reckoned 
to be the fundamental reasons for the sharing economy to origin and abrupt advance. Communal efforts reduce consumption and production volumes, enables to use energy, water, food and other finite resources more efficiently and to extend the product life cycle (Kathan et al., 2016).

- Climate change and global warming. Over the last couple of decades, meteorologists have registered drastic climate alterations caused by reckless human activities and modern lifestyles. The rising average temperature of air and the level of oceans, frequent natural disasters and extreme events endanger human existence and wellbeing. Various initiatives of sharing economy can also take action on climate change mitigation by reducing greenhouse gas emissions. According to Schor (2014), the ecological footprint can be visibly reduced by implementing consumer-based solutions in the transport sector.

- Increasing urbanization is represented not only by social but ecological problems as well. Due to the development of cities infrastructure, the densely populated areas suffer from intensified road traffic and increasing air pollution, soil and water contamination, high levels of noise, decay of biodiversity and the challenges of wasted disposal. The solutions offered by sharing economy initiatives are especially popular in building sustainable mobility programs which seek to reduce urban vehicle traffic, gas emissions and avoid traffic congestion (Cohen \& Kietzmann, 2014).

Finally, a big if not the leading role in the development of sharing economy is played by the following technological factors:
- The emergences of Internet, mobile devices and digital platforms have laid the grounds to the birth of the new economic model; emphasize both Bockmann (2013) and Goudin (2016). Without this technological breakthrough, sharing of goods and services directly between peers and no intervention of a third party would have been simply impossible.

- The expanding social networks have connected large groups of user of similar interests and hobbies, highlighted the specific needs of the online community members and involved them into economic activities as equal participants.

- Electronic commerce has also significantly contributed to the growth of sharing economy by accelerating and simplifying the whole process of procurement. Electronic payment instruments allowed buyers to pay for their purchases without cash; enhanced their confidence in online financial transactions as well as mobile transactions.

Altogether it can be stated that it was the close correlation between all previously mentioned four groups of sharing economy drivers that has led to the emergence and development of the phenomenon.

The profound examination of all the above-mentioned authors' publications led to the final outcome of this study the conceptual business model of sharing economy (Figure 5). It was designed in accordance with the hereinabove analyzed widely established characteristics, dimensions, factors and drivers of the sharing economy.

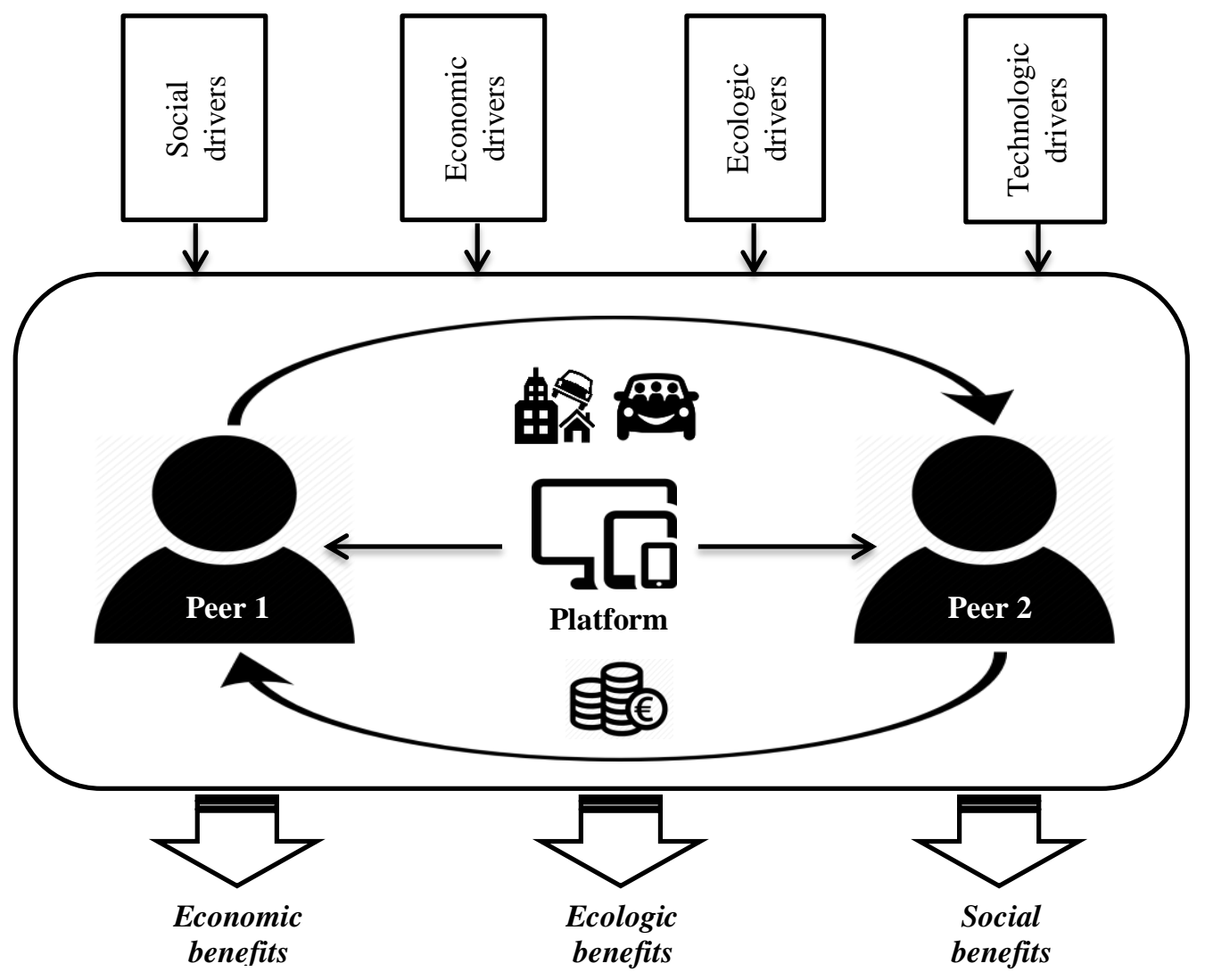

Figure 5. Conceptualization of Sharing Economy as a Business Model 
The four groups of sharing economy drivers are considered to be the input in this business model, while the process of sharing itself runs between peers via digital platforms - mobile apps, webpages, etc. The output of the sharing economy business model is the various benefits that arise from the interaction of social, economic, ecologic and technologic drivers combined together with digital means of communication. The users of sharing economy receive such economic advantages as additional income, lower prices and wider choice of goods and services, progress of personal innovation and entrepreneurship, flexible working arrangements, etc. Ecological merits of the phenomenon include efficient use of resources, saving energy resources, lower volumes of consumption and waste, reduction of ecological footprint. Finally, the social benefits of sharing economy are the rebirth of communities, development of social and communicative skills, increasing social inclusion and opportunities for social mobility.

Even the majority of researchers focus on the positive side of the sharing economy, but there are some difficulties, which may complicate the development of some initiates of the sharing economy (Bardhi \& Eckhardt, 2012; Belk, 2014; Gullstrand et al., 2016). Verboven \& Vanherck (2016) emphasizes that sharing economy business models were exposed the unexpected consequences and may cause some negative economic effects:

1) With increased choice, consumer behaviour changes and consumption even increases. This phenomenon, called the rebound effect, is particularly characteristic of markets where prices of goods are falling as a result of emerging business models. Sellers sell, rent, or lend to consumers for a fee that is usually lower than in a traditional market. If at least one side of the beneficiaries (sellers - earned extra income, or buyers - saved money because of lower fee) uses that benefit for buying other goods and services, it can be said that their primary activity causes an unwanted side effect of increasing consumption.

2) Priority is given to economic tasks, not social or ecological. Some of the sharing economy initiatives only formally declare themselves acting as environmental or social friendly incentives, although they are actually pursuing economic growth and financial gain. Together with the lack of legal regulation, this encourages the formation of monopolistic or oligopolistic markets.

3) Danger to employees' rights. Some business units in the sharing economy fail to provide stable and employeefriendly working conditions. Most of the problems are caused by working licenses, unclear employee accountability, lack of transparency, low wages.

\section{Conclusions}

The review and analysis of diverse scientific resources led the authors to a revised definition of the phenomenon: sharing economy is a modern technology-based method of whether collaboration or business management that enables the peers to allocate the already existing tangible and intangible resources free of charge or for a fee.

The key behind the emergence and rapid development of the sharing economy is the novel business model that embraces four dominant features.

The exclusive elements, typical to the phenomenon, also known as the characteristics of sharing economy that are strongly related to the modern technologies.

The dimensions of the sharing economy define the operation of collaborative platform in the terms of its users, goals and in some cases - technologies, resources and other components that are circulating in the sharing economy initiatives.

The factors and drivers of the sharing economy encompass the social, economic, ecological and technological forces contributing to the success and growth of the phenomenon.

The conceptual business model of sharing economy was constructed considering the characteristics, dimensions, factors and drivers of the phenomenon. It not only reflects the contemporary circumstances of globalization, but facilitates the comprehension of the functioning of the sharing economy and its principles as well. Moreover, it is a great asset when designing and launching new sharing economy initiatives.

The conceptual business model was developed in the paper is well constructed theoretical background of the sharing economy. Applying the model with existing or hypothetical modes of sharing of the economy and estimating their potential risks and opportunities for development is a field for our further research.

Existence of negative effects of sharing economy business models proves that the sharing economy in the context of sustainable development cannot be painted only in bright colours. Creation of greater added value requires close cooperation between three types of stakeholders: consumers, business organizations and government.

\section{References}

Bachnik, K. (2016). Sustainable Consumption through the Sharing Economy. Research Papers of the Wroclaw University of Economics/Prace Naukowe Uniwersytetu Ekonomicznego we Wroclawiu, 423, 35-44.

Bardhi, F., \& Eckhardt, G. M. (2012). Access-based consumption: the case of car sharing. Journal of Consumer Research, 39(4), 881-898. https://doi.org/10.1086/666376

Belk, R. (2014). You are what you can access: sharing and collaborative consumption online. Journal of Business Research, 67(8), 1595-1600. https://doi.org/10.1016/j.jbusres.2013.10.001

Boumphrey, S. (2016). The New Consumerism: Redefining Ownership, Values and Priorities. Available from internet: http://blog.euromonitor.com/2016/04/the-new-consumerism-redefining-ownership-values-and-priorities.html

Bocker, L., \& Meelen, A. A. H. (2016). Sharing for People, Planet or Profit? Analysing Motivations for Intended Sharing Economy Participation. Innovation Studies Utrecht (ISU) Working Paper Series, 16(02), 1-22. 
Bockmann, M. (2013). The Shared Economy: It is Time to Start Caring about Sharing; Value Creating Factors in the Shared Economy. University of Twente, Faculty of Management and Governance.

Buczynski, B. (2013). Sharing is Good: How to Save Money, Time and Resources through Collaborative Consumption. New Society Publishers.

Cheng, D. (2015). Barriers to Growth in the "Sharing Economy". Next American Economy Convening, Roosevelt Institute. Available from internet: http://rooseveltinstitute.org/wp-content/uploads/2015/10/Cheng-The-Gig-Economy.pdf

Codagnone, C., \& Martens, B. (2016). Scoping the Sharing Economy: Origins, Definitions, Impact and Regulatory Issues. JRC Science for Policy Report, Luxembourg: Publications Office of the European Union. https://doi.org/10. 2139/ssrn.2783662

Cohen, B., \& Kietzmann, J. (2014). Ride on! Mobility Business Models for the Sharing Economy. Organization \& Environment, 27(3), 279-296. https://doi.org/10.1177/1086026614546199

Dudek, D., \& Salek, R. (2016). The Concept of Sharing Goods as a Manifestation of Information Technology Transformation in Rural Areas. Zeszyty Naukowe Politechniki Częstochowskiej. Zarządzanie, (21), 124-133. https://doi.org/10.17512/znpcz.2016.1.12

Felson, M., \& Spaeth, J. L. (1978). Community Structure and Collaborative Consumption: A Routine Activity Approach. American Behavioral Scientist, 21(4), 614-624. https://doi.org/10.1177/000276427802100411

Grybaite, V., \& Stankeviciene, J. (2016). Motives for Participation in the Sharing Economy-Evidence from Lithuania. Ekonomia i Zarzadzanie, 8(4), 7-17. https://doi.org/10.1515/emj-2016-0028

Gobble, M. M. (2017). Defining the Sharing Economy. Research-Technology Management, 60(2), 59-63. https://doi.org/10.1080/08956308.2017.1276393

Gullstrand, E. E., Lehner, M., \& Mont, O. (2016). Exploring consumer attitudes to alternative models of consumption: motivations and barriers. Journal of Cleaner Production, 123, 5-15. https://doi.org/10.1016/j.jclepro.2015.10.107

Goudin, P. (2016). The Cost of non-Europe in the sharing Economy Economic, Social and Legal Challenges and Opportunities. European Parliamentary Research Service, European Added Value Unit PE.

Kathan, W., Matzler, K., \& Veider, V. (2016). The Sharing Economy: Your Business Model's Friend or Foe? Business Horizons, 59(6), 663-672. https://doi.org/10.1016/j.bushor.2016.06.006

Marshall, P. (2015). The Sharing Economy. SAGE Business Researcher. Available from internet: http://businessresearcher.sagepub.com/sbr-1645-96738-2690068/20150803/the-sharing-economy

Munoz, P. (2016). Making Sense of the Many Business Models in the Sharing Economy. Available from internet: https://www.fastcompany.com/3058203/making-sense-of-the-many-business-models-in-the-sharing-economy

Munoz, P., \& Cohen, B. (2017). Mapping out the Sharing Economy: A Configurational Approach to Sharing Business Modeling. Technological Forecasting and Social Change, 125, 21-37. https://doi.org/10.1016/j.techfore.20 17.03.035

Petropoulos, G. (2017). An economic review of the collaborative economy. Bruegel Policy Contribution, 5, 1-17.

Oh, S., \& Moon, J. Y. (2016). Calling for a Shared Understanding of the Sharing Economy. Proceedings of the 18th Annual International Conference on Electronic Commerce: e-Commerce in Smart connected World (p. 35). ACM. https://doi.org/10.1145/2971603.2971638

Schor, J. (2016). Debating the Sharing Economy. Journal of Self-Governance \& Management Economics, 4(3), 7-22. https://doi.org/10.22381/JSME4320161

Selloni, D. (2017). New Forms of Economies: Sharing Economy, Collaborative Consumption, Peer-to-Peer Economy. CoDesign for Public-Interest Services, 15-26. https://doi.org/10.1007/978-3-319-53243-1_2

Vaughan, R., \& Daverio, R. (2016). Assessing the Size and Presence of the Collaborative Economy in Europe. PwC UK, impulse paper for the European Commission.

Verboven, H., \& Vanherck, L. (2016). The Sustainability Paradox of the Sharing Economy. Umwelt Wirtschafts Forum, 24(4), 303-314. https://doi.org/10.1007/s00550-016-0410-y

Weber, T. A. (2014). Intermediation in a Sharing Economy: Insurance, Moral Hazard, and Rent Extraction. Journal of Management Information Systems, 31(3), 35-71. https://doi.org/10.1080/07421222.2014.995520

The article has been reviewed.

Received in July 2018; accepted in June 2019. 